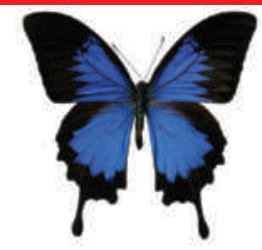

THE BUTTERFLY EFFECT GETS ENTANGLED Cold-atom experiments show chaotic fingerprints in the quantum world. go.nature.com/qz6yoY

about a lot of fields of science," he says, "so I could quickly judge their merits."

Many critics took exception to the premise of funding such large-scale, focused projects, saying that fundamental research could be losing out. For instance, on 3 October Shinichi Aizawa, president of the Japanese Society of Developmental Biologists, called for policy-makers to better balance applied research with basic science.

Yamanaka told Nature that he was reserving comment until the DPJ makes an official statement about the fate of the programme.

Atsushi Sunami, director of the science and technology policy doctoral programme at the National Graduate Institute for Policy Studies in Tokyo, also thinks that the grants are too big. "With this kind of funding, you could do more high-risk, high-return smaller projects," he says. "What will the extra funding achieve for these groups that are already funded? It's not clear. You're pouring water into something that's already full.'

But two aspects of the FIRST programme could set a good precedent for Japan, Sunami says. Grantees can take the funding to any institution they please - an attempt to introduce competition and fluidity among research centres. And the grants are given for five-year terms so that grantees don't need to rush to spend, and potentially waste, money at the end of each fiscal year.

David Cyranoski

to become both motile and self-renewing. Many aggressive secondary tumours might form from newly converted cancer stem cells, he notes, overturning the standard dogma that stem cells generate non-stem cells.

Meanwhile, Sijin Liu of Tufts University School of Medicine in Boston reported one of the first drug compounds that can directly block metastasis, in a mouse model of breast cancer. Liu showed that inhibiting the ROCK signalling pathway with a small molecule led to around $35 \%$ fewer metastases, as well as decreasing the mass of the resulting secondary tumours by nearly $80 \%$.

Until such therapies exist, however, understanding primary tumours remains a major route to indirectly mitigating metastasis, Jacks says. "It could be that we will enter an era of cancer management," he says, "in which our understanding of how tumours advance through these early stages will present us with preventative strategies to block the emergence of later lesions." Elie Dolgin

\title{
Fusion delays sow concern
}

Construction at the site of ITER - the multibillion-euro project to prove controlled nuclear fusion - has been at a standstill since April, Nature has learned.

The stoppage comes as European contributors negotiate how to pay for their share of ITER, a collaboration between Europe, Japan, South Korea, Russia, the United States, China and India. The European Union (EU) is by far the largest participant, providing some $45 \%$ of construction costs, including the buildings that will eventually house the giant machine in St Paul lez Durance, in the south of France.

Excavations for the buildings, slated to begin this autumn, will not start until spring 2010 - roughly a year after site preparations were completed.

European officials say that the reasons for the delay are technical rather than political, and that they will be able to meet the 2018 deadline for completing construction. "The project is not on standby," says Catherine Ray, a spokeswoman for research for the European Commission in Brussels.

But some researchers are concerned that the political impasse could push back ITER's start date. "I'm worried that whatever we lose now could delay the project's completion," says Günther Hasinger, scientific director of the Max Planck Institute of Plasma Physics in Garching, Germany.

When completed, the machine will heat and compress hydrogen isotopes until they

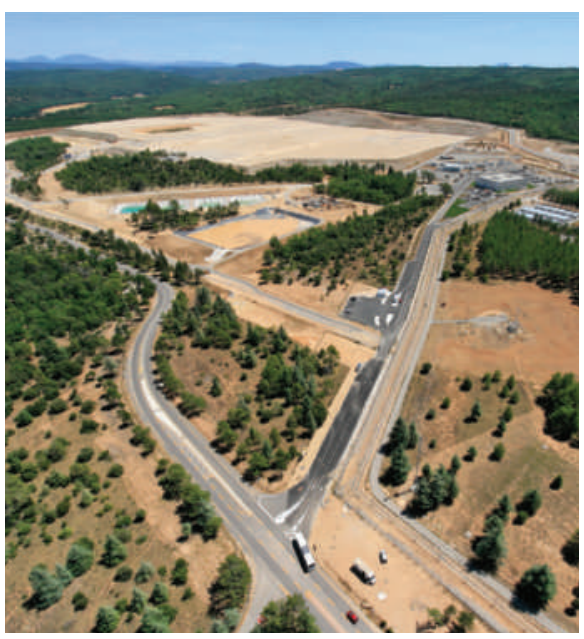

The ITER site: ready for buildings. fuse into helium, releasing energy.

In 2006, ITER was slated to cost around $€ 5$ billion (US $\$ 7.4$ billion) to construct and another $€ 5$ billion to operate over a 20 -year period. But following an extensive design review, the construction costs are now expected to at least double (see Nature 459, 488 ; 2009).

Ray says that the EU had budgeted nearly $€ 10$ billion for construction, operation and decommissioning over a 35-year period. But now the $27 \mathrm{EU}$ member states, plus Switzerland, must come up with additional commitments to cover the cost increase. Hasinger says that until they provide a plan for funding, construction is unlikely to begin. "The problem in the European situation is that they need the whole commitment for construction before they can award the contracts," he says.

Sources close to the negotiations say that a number of options are being considered. One would be to secure additional commitments from member states. Another would be a promise from the European Investment Bank, headquartered in Kirchberg, Luxembourg, to provide loans for any additional funds needed.

Such a loan scheme would not be unprecedented: in 2002 CERN, Europe's high-energy physics laboratory near Geneva, Switzerland, took out a $€ 300$-million loan to pay for construction costs for the Large Hadron Collider particle accelerator.

Officials say that the situation is under control. Although the budget delays could cause problems down the line, "I am not limited by the amount of money for right now," says Didier Gambier, the director of Fusion for Energy in Barcelona, Spain, which oversees the contracts for ITER's buildings.

Gambier says that the decision to delay contracts was purely technical, and driven in part by the fact that the design of ITER is still being finalized. "We still need to have more information from the other parties," he says. Nevertheless, he says, "we are pushing as hard as we can".

ITER is expected to be completed in 2018 and to conduct its first power-producing experiments in 2026.

Geoff Brumfiel 